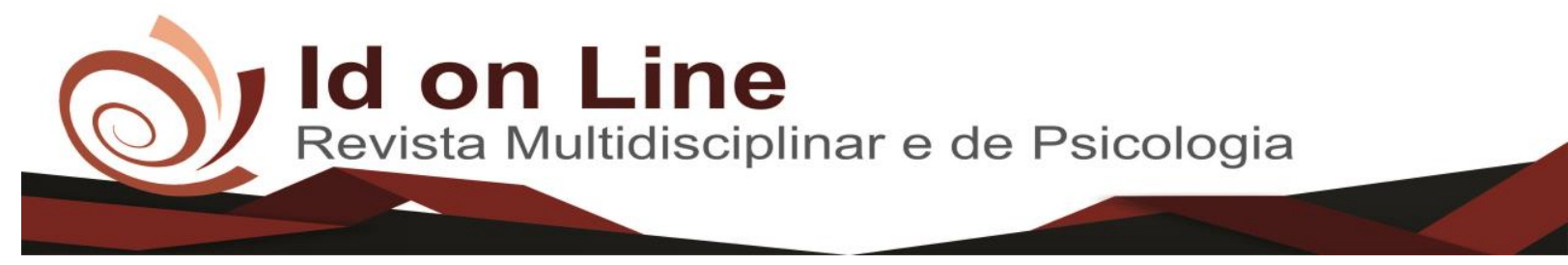

Artigo

\title{
As Diretrizes Curriculares Nacionais - 1998 e o Plano Nacional de Educação 2001 - 2010
}

\author{
Maria Belo Silva Lima' ; Meryelle Macedo da Silva²; Sebastiana Micaela Amorim Lemos ${ }^{3}$
}

Resumo: A educação é inerente ao desenvolvimento social, à medida que tende a transformar os educandos em cidadãos críticos e conscientes da realidade. Entretanto, a compreensão de educar, no Brasil, restringe-se a formalidade da escola, e a instrução, no sentido de adaptação do aluno a sociedade e não na transformação desta. Corrobora para tal fato, a inexistência de políticas de Estado e a permanência de políticas de governo, que se adequam aos grupos partidários que estão no poder. Diante desse contexto, o referido estudo analisou marcos importante da história da educação brasileira, a saber, as Diretrizes Curriculares Nacionais de 1998 e o Plano Nacional de Educação 2001-2010 e as contribuições e limitações dos referidos documentos para a educação brasileira.

Palavras-chave: Políticas Educacionais - Diretrizes Nacionais - PNE 2001-2010.

\section{The National Curriculum Guidelines - 1998 and the National Education Plan 2001-2010}

\begin{abstract}
The education is inherent to the social development, as it tends to transform the students in critical citizens and conscious of the reality. However, the understanding of educating, in Brazil, limits the formality of the school, and the instruction, in the sense of the student's adaptation the society and not in the transformation of this. It corroborates for such fact, the inexistence of politics of State and the permanence of government's politics that are adapted to the supporting groups that are in the power. Before of that context, referred him study analyzed marks important of the history of the Brazilian education, to know, the Guidelines National Curriculum 1998 and the National Plan of Education 2001-2010 and the contributions and limitations of the referred documents for the Brazilian education.
\end{abstract}

Keywords: Education politics - Guidelines National - PNE 2001-2010.

\footnotetext{
${ }^{1}$ Licenciatura em Pedagogia pela Universidade Regional do Cariri . Bacharel em Direito pela Universidade Regional do Cariri. Aluna do Mestrado Profissional em Educação da Universidade Regional do Cariri. Especialização em Metodologia do Ensino e em Direito Constitucional pela Universidade Regional do Cariri - URCA.

${ }^{2}$ Graduação em Geografia pela Universidade Regional do Cariri. Docente na Escola de Ensino Fundamental e Médio Teodorico Teles de Quental na Cidade do Crato- CE e Na Escola de Ensino Médio Adauto Bezerra no município de Barbalha- CE. Especialização em Geografia e Meio Ambiente, Graduanda em pedagogia e Mestranda do Programa de Mestrado Profissional em Educação, da Universidade Regional do Cariri-URCA.

${ }^{3}$ Mestranda em Educação pela Universidade Regional do Cariri. Professora Temporária da Universidade Regional do Cariri - URCA, Unidade de Campos Sales. Graduada em Ciências Biológicas (Licenciatura) pela Universidade Regional do Cariri - URCA. Contato: micaela_lemos@hotmail.com.
} 


\section{Introdução}

Os anos que se seguem a proclamação da Constituição Federal de 1988, considerada uma constituição cidadã, feita pelos representantes do povo, fruto da luta por um processo de redemocratização, já que o país tinha passado por anos sob a égide de um sistema militar. Um momento onde os direitos e garantias fundamentais do ser humano ficaram em suspenso e foram marcados por grandes discussões de professores e demais profissionais da educação, sobre a garantia de qualidade e permanência da população infantil e juvenil na escola, bem como de uma educação pública, gratuita e de qualidade.

$\mathrm{Na}$ Constituição Federal o direito a educação aparece como um direito social ou de $2^{\mathrm{a}}$ geração. O próprio texto constitucional, embasado nos princípios de igualdade e diversidade, estipula conteúdos mínimos para assegurar uma formação básica comum para o Ensino Fundamental.

Baseada nesse ideário de educação surge a Lei de Diretrizes e Bases da Educação n ${ }^{\circ}$ 9.394/96 que vem tratar de forma mais especializada e direcionada o direito a educação. Em seu art. $9^{\circ}$, IV afirma ser incumbência da União, em colaboração com estados, distrito federal e municípios, estabelecer diretrizes para nortear os currículos e seus conteúdos mínimos de forma que assegure a formação básica comum.

Nesse processo evidencia-se o papel fundamental do currículo na estrutura educacional e no fazer pedagógico, por isso, foram realizados vários esforços pautados em reformas estruturais e curriculares objetivando a ampliação e melhoria da escola pública.

Dentre essas ações temos a implantação das Diretrizes Curriculares Nacionais em 1998 e, posteriormente, o Plano Nacional de Educação de 2001 a 2010 propostos pelo Conselho Nacional de Educação/MEC. Esse órgão tem papel consultivo e uma de suas funções é deliberar sobre as diretrizes curriculares propostas pelo Ministério da Educação e do Desporto.

\section{As Diretrizes Curriculares Nacionais}

As Diretrizes Curriculares Nacionais para o Ensino Fundamental (DCN's) em resposta aos Parâmetros Curriculares Nacionais (PCN's) pauta-se, basicamente, “em três documentos 
feitos pela Câmara de Educação Básica do CNE: a Exposição de Motivos ao encaminhamento das DCN's (Brasil, 1997), a Resolução nº 2 de 7/4/1998 (Brasil, 1998) e o Parecer da CEB nº 4/98 de 29/1/1998 (Brasil,1998) " (BONAMINO \& MARTINEZ, 2002, p. 373)

Para deliberação dos conteúdos mínimos da formação básica comum observa-se que o CNE além dos PCN's, apoiam-se, na CF, na LDB, na Lei n. ${ }^{\circ} 9.131 / 95$ e na Lei n. ${ }^{\circ}$ 8.069/90 Estatuto da Criança e do Adolescente.

A Resolução n 2, de abril de 1998 apresenta as Diretrizes Curriculares Nacionais DCN’s como um conjunto normativo para a organização da educação básica, orientado as escolas públicas e privadas acerca da organização, desenvolvimento e avaliação das suas ações pedagógicas.

O Parecer da CEB n 4/98 e a Resolução no 2 de 1998, propõem sete diretrizes como referência para a organização do currículo escolar. Segundo Bonamino \& Martinez (2002, p. 375-377) são essas:

1) as escolas deverão fundamentar suas ações pedagógicas em princípios éticos, políticos e estéticos (Brasil, 1998a, p. 01);

2) reconhecer a identidade de todos que atuam na educação escolar, isto é, perceber todos os sujeitos a partir de suas particularidades. Além disso, aponta para acolhida democrática das diversidades e peculiaridades de gênero, étnicas, etárias, culturais e socioeconômicas dos educandos;

3) considera o processo educacional como uma relação indissociável entre conhecimento, linguagem e afetividade, que constituem o ato de ensinar-aprender;

4) estabelece conteúdos curriculares mínimos para a chamada Base Nacional Comum, destinados a legitimar a unidade e a qualidade da educação nacional. Constitui a BNC Língua Portuguesa, Língua Materna (indígenas e migrantes), Matemática, Ciências, Geografia, História, Língua Estrangeira, Educação Artística, Educação Física e Educação Religiosa (Brasil, 1998b, p. 7). Junto a essas disciplinas deve-se trabalhar a denominada parte diversificada, onde se discute questões para a cidadania;

5) orienta as escolas a conduzir as propostas curriculares e a prática educativa a articular os conhecimentos e valores da Base Nacional Comum e da Parte Diversificada ao contexto social;

6) elucida a autonomia escolar e a orienta no usos da Parte Diversificada do currículo no desenvolvimento de atividades e projetos de seu interesse, e 
7) aponta para propostas pedagógicas que zelem pela cooperação e de condições básicas para planejar os usos do espaço e do tempo escolar, da relação entre escola e comunidade.

Ao fazer um paralelo entre as Diretrizes e os Parâmetros Curriculares observa-se uma dicotomia entre os documentos legais, onde evidencia o caráter não obrigatório desse último, o que se evidencia na exclusão de suas referências na definição dos princípios das Diretrizes Curriculares Nacionais.

Após a divulgação das Diretrizes Curriculares Nacionais em 1998, surge a necessidade de elaborar um plano educacional com o objetivo de aprimorar a oferta e qualidade do ensino em nosso país.

\title{
O Plano Nacional de Educação 2001-2010
}

O Plano Nacional de Educação - PNE é um documento que objetiva fundamentar toda a estrutura educacional do país com o intuito de melhorar a qualidade do ensino. Baseado na Carta Magna que em seu art. 214 determina:

\begin{abstract}
A lei estabelecerá o plano nacional de educação (PNE) de duração de dez anos como objetivo de articular o sistema nacional de educação em regime de colaboração e definir diretrizes, objetivos, metas e estratégias de implementação para assegurar a manutenção e desenvolvimento do ensino em seus diversos níveis, etapas e modalidades por meio de ações integradas dos poderes públicos das diferentes esferas federativas (BRASIL, 1988).
\end{abstract}

E somado ao que rege o art. $8^{\circ}, \S 1^{\circ}$ da LDB 9394/96 que dá a Uniao competência para coordenar a política nacional e educação, articulando os diferentes níveis e sistemas de ensino e exercendo função normativa. Surge, através da Lei nº 10.172, de 9 de janeiro de 2001, o Plano Nacional de Educação.

Essa necessidade está atrelada as mudanças significativas ocorridas na sociedade brasileira e mundial que compreendem a educação como um dos principais fundamentos para o desenvolvimento de um país. Vivendo numa época neoliberal, onde há uma forte disputa econômica e ideológica entre setores industriais, financeiros e institucionais, a necessidade de 
desenvolvimento no país surge com toda força, embora, muitas vezes, a ideia de educação restringe-se a de instrução.

Ao analisarmos a história da educação em nosso país evidencia-se uma primeira tentativa de um plano nacional de educação a partir do Manifesto dos Pioneiros da Educação no ano de 1932 que propunha, dentre outras coisas, um plano de caráter unitário e científico na tentativa de uma reconstrução da educação brasileira.

Como documento de política educacional, mais do que a defesa da Escola Nova, está em causa no "Manifesto" a defesa da escola pública. Nesse sentido, o texto emerge como uma proposta de construção de um amplo e abrangente sistema nacional de educação pública abarcando desde a escola infantil até a formação dos grandes intelectuais pelo ensino universitário [...] (SAVIANI, 2008, p. 253).

É relevante salientar que o manifesto foi pensado por um grupo de intelectuais, pertencentes à elite brasileira, no intuito da perpetuação hegemônica quanto à política educacional. Diante dessa perspectiva a ambiência escolar, embora não deixando de evidenciar a cultura da literatura e da arte, seria promotora de um arcabouço mais científico e técnico, necessário a nova realidade produtiva da sociedade (SAVIANI, 2008).

O ideário do documento acabou sendo reduzido a inserção dos artigos 150 e 152 da Constituição Brasileira de 1934 que declarava ser competência da União fixar um plano nacional de educação direcionado a todos os graus e ramos da educação no país, cabendo ao Conselho Nacional de Educação elaborá-lo e submetê-lo a aprovação do Poder Legislativo. Cabia, assim, ao Poder Público destinar orçamento necessário para a efetivação da qualidade da escola brasileira.

Em 1961 é editada a Lei n. ${ }^{\circ}$ 4.024, a primeira Lei de Diretrizes e Bases da Educação Nacional e em sua vigência surge o Plano Nacional de Educação em 1962, com um conjunto de metas a serem alcançadas no prazo de oito anos e elaborado pelo Ministério da Educação e Cultura aprovado pelo Conselho Federal de Educação. No ano de 1965 ocorre alterações no texto incorporando normas descentralizadoras para elaboração de planos nos estados. No ano seguinte, fruto de uma revisão textual, estipula-se distribuição de recursos federais para a implantação de ginásios com a finalidade de atender a população não alfabetizada com idade superior a dez anos, embora essa ideia não tenha se concretizada na prática. 
É somente com a proclamação da Constituição Federal de 1988 que o plano nacional de educação ganha força de lei, garantindo estabilidade as iniciativas governamentais na área educacional.

Fruto de grandes debates nacionais e mundiais a proposta do Plano Nacional em Educação - PNE teve como base as discussões do Plano Decenal de Educação para Todos, organizado a partir das recomendações da UNESCO realizada em Jomtien, na Tailândia, em 1993; além das propostas de várias entidades como o Conselho Nacional de Secretários de Educação - CONSED e da Uniao Nacional dos Dirigentes Municipais de Educação UNDIME.

Apresentando 295 metas para toda a Educação Básica e o Ensino Superior, o plano aprovado deixa de ser uma mera carta de intenções para ser um rol de obrigações, tendo um caráter imperativo. Dentre suas metas temos:

\footnotetext{
A elevação do nível de escolaridade de toda a população; a melhoria da qualidade do ensino em todos os níveis; a redução das desigualdades sociais e regionais na educação pública e democratização da gestão do ensino público, nos estabelecimentos oficiais, obedecendo aos princípios da participação dos profissionais da educação na elaboração do projeto pedagógico da escola e a participação das comunidades escolar e local em conselhos escolares (BRASIL, PNE, 2000, p. 14)
}

O Plano Nacional de Educação constitui uma ferramenta elementar para a melhoria da educação no país, no entanto, seu alcance efetivo está relacionado a função política educacional a ser implementada, ao ordenamento jurídico que lhe dá suporte e das condições humanas, materiais e financeiras à disposição da sociedade. Como ressalta Saviani, o sistema nacional de ensino:

\footnotetext{
Não pode ser uma unidade monolítica, indiferenciada, mas unidade da diversidade, um todo que articula uma variedade de elementos que, ao se integrarem ao todo, nem por isso perdem a própria identidade; ao contrário, participam do todo, integram o sistema na forma de suas respectivas especificidades (2010, p. 382).
}

Podemos afirmar, conforme Cury, que o Plano Nacional deve concretizado conforme um período cronológico, "dentro de objetivos a serem atingidos e para os quais se pleiteiam os meios, inclusive pecuniários, necessários para a implementação adequada" (1998, p. 164). 
Nesse contexto, o Plano Nacional de Educação pretende que se estabeleçam políticas de Estado, a partir da participação ampla e democrática da sociedade civil, visando a realizar e garantir - com qualidade - os direitos educacionais para todos.

Por isso que não basta somente a garantia da lei é necessário políticas públicas educacionais que possibilitem a efetivação do que está regulamentado. No entanto, infelizmente, em nosso país é comum observarmos que as conquistas legais nem sempre se evidenciam na realidade cotidiana das pessoas.

Ao analisarmos o PNE 2001-2010 observa-se que muitas metas não foram cumpridas e há várias críticas acerca do mesmo, dentre elas temos: enorme quantidade de objetivos e metas, talvez, por isso, o segundo PNE tenha sido constituído de vinte metas; "alto índice de dispersão e perda do senso de distinção entre o que é principal e secundário" (Saviani, 2007, p.255); as diretrizes e metas denotam a "carência de organicidade interna do Plano", posto que diversas metas sejam reiteradas, por vezes superpostas (Dourado, 2010, p.684) e por não apresentar a devida articulação interna, especialmente no que se refere a concepções, financiamento e gestão.

Diante dos avanços e das críticas ao PNE de 2001 foi realizada a Conferência Nacional de Educação -CONAE em 2010, fruto dos movimentos que envolveram a sociedade política e civil que, de alguma forma, estão vinculados à educação para discutir os rumos da educação brasileira, principalmente para definir os subsídios necessários à elaboração do PNE para os próximos dez anos.

Apesar de todas as limitações podemos concluir que os Planos de Educação é um dos instrumentos utilizados contra a descontinuidade das políticas, pois orientam a gestão educacional e acaba dando certo controle social acerca das ações governamentais ligadas a educação. Em nosso país é evidente a falta de uma política educacional que ultrapasse os planos de gestão governamental, pois, a cada novo governo surge novas ideias para atender as necessidades partidárias e governamentais dos mesmos e não há continuidade progressiva das políticas educacionais implantadas em prol das necessidades reais dos educandos e do sistema de ensino como um todo. 


\section{Considerações Finais}

Através do referido estudo, analisamos as Diretrizes Curriculares Nacionais e o Plano Nacional de educação 2001-2010. As DCN's, então propostas pelo Parecer da CEB n 4/98 e a Resolução $\mathrm{n}^{\mathrm{o}} 2$ de 1998, se constitui em um documento amplo, que aborda uma grande diversidade de problemas, bem como apresentam perspectivas e propostas diversificadas, abrangendo desde a veiculação de questões éticas, estéticas e políticas até sugestões sobre procedimentos e competências que deveriam integrar uma base comum nacional dos currículos.

O PNE 2001-2010 aprovado pelo Congresso se traduz na compreensão de que a política educacional deve ser concebida e praticada conforme o pensamento e as reivindicações da comunidade escolar. Porém não contempla as propostas e reivindicações dos setores democráticos e populares da sociedade, pela enorme quantidade de objetivos e metas, além de não apresentar a devida articulação interna, especialmente no que se refere a concepções, financiamento e gestão.

Os documentos analisados apresentam uma tentativa de organização e funcionamento da educação escolar brasileira, mas tem como finalidade o atendimento as perspectivas e interesses de um sistema de governo ligados as necessidades e exigências da economia mundial, mas, precisamente, as diretrizes do Banco Mundial. Não constituindo, assim, na sua essência uma proposta política de organização e funcionamento da educação de Estado, pois, a cada mudança de governo, altera-se os objetivos e metas para atender a um determinado grupo político e não se pensa numa estrutura que atenda a comunidade em geral, dando continuidade aos avanços e dirimindo os aspectos negativos de cada proposta educacional.

Nesse sentido, as Diretrizes Educacionais e os Planos Nacionais de Educação, apesar de constituírem documentos estruturantes do sistema educacional, não dão conta, por si mesmos, de resolver os problemas encontrados dentro das instituições de ensino, se faz necessário proposta e práticas políticas que gerenciem, fiscalizem e atuem de forma que a educação seja compreendida como um elemento de emancipação individual e social, uma proposta não de um governo, mas de toda a sociedade brasileira. 


\section{Referências}

BRASIL. Constituição (1988). Constituição da República Federativa do Brasil. Brasília, DF: Senado Federal, $1988 . \quad$ Disponível em: http://www.senado.leg.br/atividade/const/con1988/con1988_07.05.2015/art_214_asp.

Acessado em: 09 de setembro de 2017.

. Lei 9.131, de 24 de novembro de 1995. Altera dispositivos da lei 4024, de 20 de dezembro de 1961, e dá outras providências. Diário Oficial da União. Edição extra. Brasília, DF, 25 nov. 1995.

Lei 9.394, de 20 de dezembro de 1996. Estabelece as Diretrizes e Bases da Educação Nacional. Diário Oficial da União. Brasília, DF, v. 134, n. 248, dez. 1996.

Ministério da Educação e do Desporto. Conselho Nacional de Educação. Câmara da Educação Básica. Exposição de motivos ao encaminhamento das Diretrizes e Bases da Educação Nacional. Brasília, DF: CNE, 1997.

Ministério da Educação e do Desporto. Conselho Nacional de Educação. Câmara da Educação Básica. Resolução n. 2, de 7 abril de 1998. Institui as Diretrizes Curriculares Nacionais para o Ensino Fundamental. Diário Oficial da União. Brasília, DF, 15 abr. 1998a.

Ministério da Educação e do Desporto. Conselho Nacional de Educação. Câmara de Educação Básica. Parecer CEB n. 4/98. Diretrizes Curriculares Nacionais para o Ensino Fundamental. Brasília, DF: MEC/CNE, 1998b.

- Ministério da Educação e do Desporto. Plano Nacional de Educação- PNE. Brasília - DF: MEC/CNE, 2000. Disponível em: http://portal.mec.gov.br/arquivos/pdf/pne.pdf. Acessado em 09 /11/2017.

Lei $n^{o} 10.172$, de 9 de janeiro de 2001. Aprova o Plano Nacional de Educação e dá outras providências. Diário Oficial da União - Seção 1 - 10 de janeiro de 2001. Disponível em: http://www.planalto.gov.br/ccivil_03/leis/leis_2001/110172.htm. Acessado em: 12/10/2017.

BONAMINO, Alicia e MARTINEZ, Silvia A. Diretrizes e Parâmetros Nacionais para o Ensino Fundamental: a participação das instancias políticas do Estado. In.: Rev. Educ. Soc. Campinas. Vol. 23. n. ${ }^{\circ}$ 80, set/2002. Disponível em: http:///www.cedes.unicamp.br

Acessado em 10 de setembro de 2017.

CURY, Carlos Roberto Jamil. O Plano Nacional de Educação: duas formulações. Caderno de Pesquisa nº 104, p. 162-180, jul. 1998.

SAVIANI, Dermeval. História das ideias pedagógicas no Brasil. $2^{\mathrm{a}}$ ed. rev.e ampl. Campinas - SP: Autores Associados, 2008. 
Sistema Nacional de Educação articulado ao Plano Nacional de Educação. Revista Brasileira de Educação v. 15 n. ${ }^{\circ} 44$, maio/ago. 2010.

SILVA, T.T.; MOREIRA, A.F. (Orgs.). Territórios contestados: o currículo e os novos mapas políticos e culturais. Petrópolis: Vozes, 1995.

\section{Como citar este artigo (Formato ABNT):}

LIMA, Maria Belo Silva; SILVA, Meryelle Macedo da; LEMOS, Sebastiana Micaela Amorim. As Diretrizes Curriculares Nacionais - 1998 e o Plano Nacional de Educação 2001 - 2010. Id on Line Rev.Mult. Psic., 2018, vol.12, n.41, p.825-834. ISSN: 1981-1179.

Recebido: 10/07/2018

Aceito 20/07/2018 